\title{
A Design of Personnel Management System Based on WEB
}

\author{
Huabo Xiao \\ College of Information Engineering, Jiangxi University of Technology, Jiangxi Nanchang
}

Keywords: Personnel management; Information system; The Internet; Personnel documents

\begin{abstract}
With the development and popularity of computers, as well as the expansion of the Internet technology, personnel management is doomed to be paperless and merged in the Intranet of the company or the Internet. We can realize the share of data and then facilitate the use of information source and update it in a timely manner. Thus the labor is saved, and the efficiency can also be improved. This paper aims to analyze the requirement for personnel management system first, then complete the system design and finally do the test. The system designed in this paper can manage archives and departments etc.
\end{abstract}

\section{Introduction}

As the human resources in companies have been increasingly huge and complicated, the mode of human and computers can no longer fit the requirements of personnel management nowadays. It will be replaced by a personnel management system developed with the knowledge of various fields and the computer science which can manage the personnel information archives in companies and expand the human resource manage ment system. The emerging MIS (Management Information System) has appeared, which covers several fields and forms a whole set of scientific and reasonable methods for information collection and processing, thus building an intertwined system. The personnel management system is a typical management information system (MIS) and its development includes the building and maintenance of the background database, and the development of the front-end application. For the former, we need to build a database with the consistency of information, full integrity and high security of the information. As for the latter, a system with complete functions and easy access is also needed. The personnel management system aims to realize the management of all personnel, and realize convenient input, query, modification, deletion and exit. It should control the change of personnel all the time and provide a comprehensive solution for a company's human resources management more readily. Based on such analysis, we use the DreamWeaver as the tool for development, to use its various subject-oriented development tools especially the data window as it can manipulate intelligence database objects simply and easily. At first, a prototype of the system is established in a short period, and then demand iteration is carried out for the initial prototype and modified and improved repeatedly until a feasible system is formed.

The concept of Management Information System was first proposed by an American J. D. GALLAGHER in 1961. This is an emerging comprehensive subject combining the management science, information science, system science as well as computer science. It studies the whole process of information management activities in a company, to achieve 
effective information management, provide information for various management decisions and assist the company to realize modern management.

The personnel management system is the information system of a company, which can process data, plan, control, predict and assist the function of decision-making, and its detailed functions are as follows:

(1) Process and provide information under the united standard, and exclude the incomplete data which is inconsistent before and after the use.

(2) Provide the complete data needed in management and decision making in a timely manner.

(3) Use the designated data relation formula to analyze the data and predict the future objectively.

(4) Provide reports with different levels of details to the management organs of different levels to shorten the time of analysis and explanation.

(5) Provide the information which is as accurate and reliable as possible at the least cost and in the shortest time, thus to provide the decision makers with the optimal solutions and improve the company's economic benefits and win the market in the competition.

\section{Requirement Analysis}

Feasibility Analysis. On Technology:

The whole system is a MIS system. Though it may be very complicated, verbose and uncertain, regarding the technology structure of the whole system, it is still a system of database application. Its basic operation is to add, delete, search and edit the existing database. Therefore, there will not be any technological challenges in the pure database application.

On Financials:

As the system casts quite huge influences on the common operation of the company, we need to set an individual server to run this system. In addition, regarding the fact that all hardware and software of the computer may malfunction (as for this system which needs to work uninterruptedly, it will be more possible for it to make any mistakes), we need to use duplicated hot-redundancy technology in the whole system. This technology is implemented with two servers simultaneously, one of which is used as the major server and the other as backup, avoiding the effects of the sever malfunction on the whole system. As this system will serve the internal company and the set and debugging of database shall be made directly on the servers, so we need to set the servers in the company. Therefore, through a general survey of the hardware needed in this system, we believe there will be a huge investment in this program. We will report this to the company for more detailed discussions.

On Laws:

This system is developed and used independently, so there will not be legal disputes on its copyright. As for the software of the server, we should insist on using the legitimate copies. Though this system is developed for internal use, many of its functions rely on the Internet. Once connected to the Internet, it operation system will be monitored by Microsoft. We may be faced with civil procedures if the software is not a legitimate copy.

The Existing Problems:

The biggest problem we face now is the access mode to database. Different from the common MIS systems, we are faced with a wider scope of database access. This scope is far 
beyond the local area network, and there will be serious threat to the effective ness and security of the data transmission once connected to the Internet.

Functional Requirements Analysis. Two issues are to be dealt with in the functional requirements analysis:

(1) Content Requirement: investigate the data needed in the operation of the system users, and decide what data shall be stored in the database.

(2) Processing Requirement: investigate processing needed by the system users and clear up the relation of the data in the database.

The development of this system is aimed to help the company's Human Resources Department work more efficiently and realize the systematization, standardization and automation of the personnel information management in the company. The main functions achieved in the system are as follows: [1]

(1) About system: mainly accomplish the task to maintain this system.

(2) About personnel's basic information: mainly accomplish the management of the basic information of the personnel

(3) About the information of the employees' holidays: mainly accomplish the management of the information of employees' holidays.

(4) About employees' skills: mainly accomplish the management of the information about employees' skills.

(5) About the management of database: mainly accomplish the management and maintenance of the database.

The personnel management system is a modern and professional management system which collects and manages the divided information of employees in enterprises and public institutions in a united, concentrated and uniform manner. It classifies and numbers the information, stores it on the computer and manages fire-proof, moist-proof, moth-proof and anti-theft, which removes the future problems for the enterprises and public institutions and their employees.

The personnel management system for enterprises can provide services like information query, information search, information storage and retrieval. This system can basically meet the needs of personnel management in modern enterprises. The input of the information is complete, integrated and systematic. Modern personnel management system can flexibly use tables to classify various information to build an enterprise's personnel management system for convenient query, reading, modification, exchanges and reuse.

The personnel management system is a modern and professional management system which collects and manages the divided information of employees in enterprises and public institutions in a united, concentrated and uniform manner. It classifies and numbers the information, stores and queries it on the computer. The documents management system can provide enterprises and public institutions with services like information query, document search, document storage and retrieval, the adjustment of wages, the issue of various certifications according to the documents, and services on collecting, collating and storing archives.

The object of the enterprise personnel management system includes enterprises, the public institutions with enterprise-style management and the employees themselves. 
The automation of the enterprise's archive management is the trend of development nowadays. The input of the information is complete, integrated and systematic, which meets the need of modern enterprise archive management system.

Modern personnel management system can flexibly use tables to classify various information to build an enterprise's personnel management system for convenient query, reading, modification, exchanges and reuse.

The whole task to develop the enterprise archive management system is to realize the systematization and automation of the archives of employees in enterprises.

The archive management system can provide enterprises and public institutions with services like information query, document search, document storage and retrieval, the adjustment of wages, the issue of various certifications according to the documents, and services on collecting, collating and storing archives.

The main functions of this system are as following:

(1) About the management of the archives of employees: the input of employee information, which includes the basic archives of employees, their family members, working records, rewards and punishments, the professional title appraisal, training records, job changes records and so on. The main function in this part is to add, modify, delete and search the information of employees.

(2) About the management of departments: the input of information of departments where an employee works includes the name of the department, its director and its contact number etc. The main function in this part is to add, modify, delete and search the information of departments.

\section{System Design}

General Design. The personnel management system mainly contains information in various aspects such as employees' personal information, cumulative holidays, phone book and employee skill records, and its content is large and complex. Meanwhile, based on a comprehensive consideration of the nature of archives management, the functions to be implemented are summarized. The system is aimed to provide service for personnel archives, including information consultation, archive retrieval, archive access and issuing all kinds of documents according to archives and so on; to realize the transition of personnel archives, as well as the query, sorting and statistics of personnel data and so on.

The major functions of this system are as follows:

The management of employee archives: the input of information related to employees, including basic archives, work records, leave situation, review schedules and phone numbers and so on.

The main function of this part should be the addition, modification, deletion and query of employee information.

The part of department management: the input of information of departments employees work in, including the name of the department, head of departments and department contact numbers and so on. The main function of this part should be the addition, modification, deletion and query of department information.

Fig. 1 is the model of the personnel management system: 


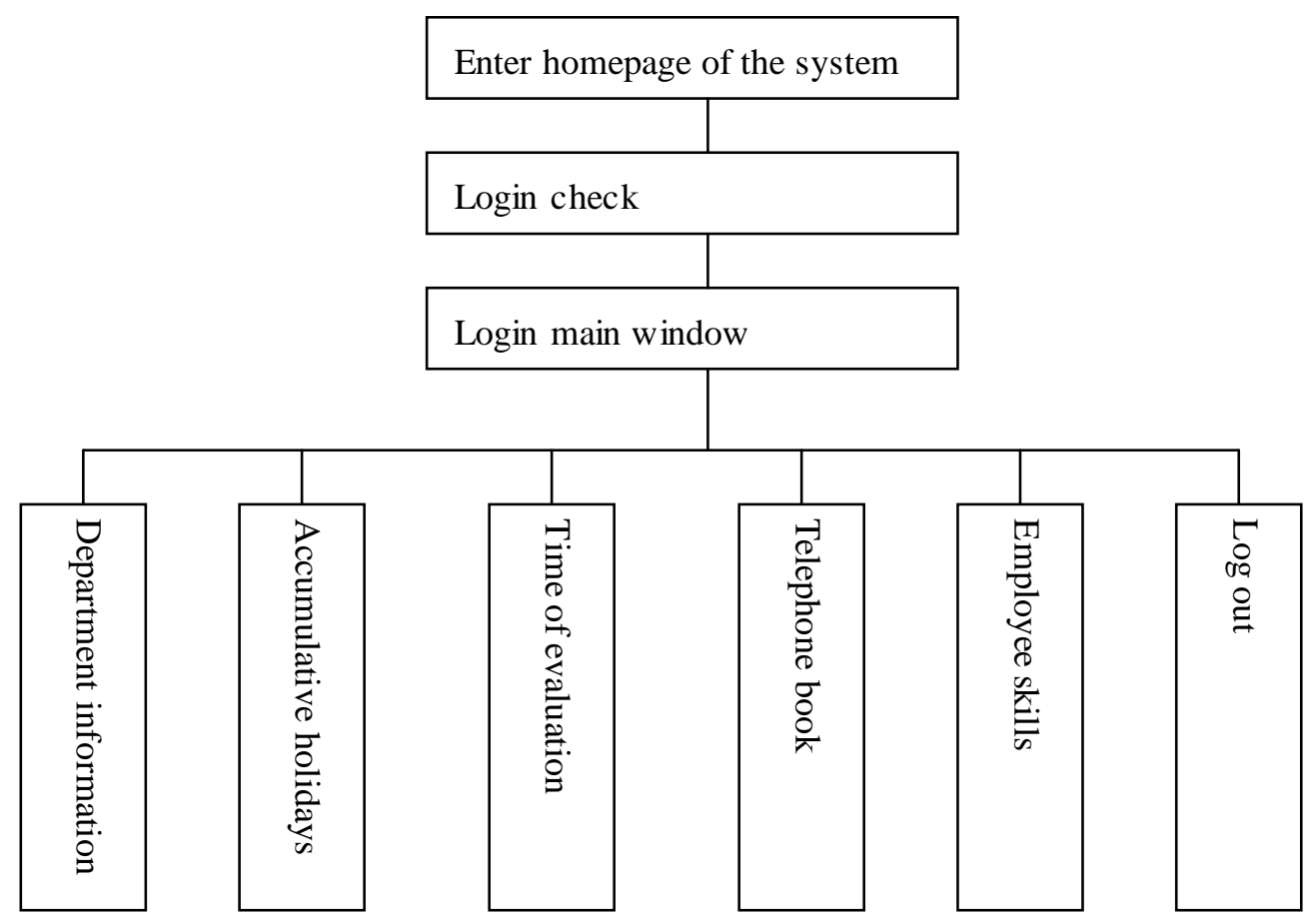

Fig. 1 System model diagram

This is a relatively complex system, but there are a lot of public modules. In order to avoid repeating writing, we need to write some of the Bean and implement modules with centralized functions in a Bean as far as possible, and then simply call in the JSP page.

Detailed design of the systemfunctions. The part of login check

First, look at the homepage of the system. On the left side of the page are links to all functions of the system, where the function framework is given. Considerations for using the system are given on the right. First, we must log in before browsing any page. Let us try bypassing the login to enter the system. Without logging in, when clicking the link of "department information", we will see a prompt that requires us to log in.

Click other links will also trigger the same page, and only when clicking "log out", the text on the page will change.

Any user who attempts to bypass the login and use the system will be redirected to the error prompt page. This function is implemented because such a line of code is contained in the beginning of every page corresponding to these links:

$\langle \% @$ include file='EnsureUserLoggedIn.jsp'\%〉

Force login is guaranteed by EnsureUserLoggedIn.jsp.

In EnsureUserLoggedIn.jsp, the login check function is implemented mainly by using the JavaBean of SessionManager. [6]

At this moment when clicking the login link, the login page will appear.

Prevent repeated login

The login module also plays a role of preventing repeated login. When the same user logs in on different machines, the machine the user logs in later will display an error prompt of repeated login, and asks the user to log out. 
Apart from the two Beans UserCredentials and SessionManager introduced above, the implementation of these functions also relies on several JSP files: Login.jsp, LoginFirst.jsp, ValidateUser.jsp, Welcome.jsp, LoginFailure.jsp, DuplicateLogin.jsp and so on.

Login.jsp divides the code into two sections by jud ging whether a user logs in the system. When the user has logged in the system, the page will be redirected to LoginFirst.jsp, and requires the user to first $\log$ off and then $\log$ in; if the user has not logged in, the page will display HTML form, to ask the user to complete the login information and submit it to ValidateUser.jsp for processing.

By calling SessionManager, ValidateUser.jsp determines whether a user logs in repeatedly, whether the account number and password are correct, as well as the way to handle incorrect login.

Check the department information

After logging in successfully, click the link of "department information" to check an employee's department information, and first the name of the department where the employee works will be displayed.

Check the accumulative holidays

After login, click the link of "my holiday", we can check an employee's holiday information.

Check the schedules

On the homepage, the link of "check schedules" is similar to that of accumulative holidays, the JSP file needed is NextReview.jsp.

Telephone book

When clicking the "telephone book", a page for checking an employee's phone number will appear. On the page, any query condition can be selected: first name of the employee, the initial letter of the first name of the employee and the name of the department etc. The $n$, the query function can be implemented by clicking "generate number form".

The query of employee skills

For a company, it is essential to grasp the expertise and skills of employees. This system provides the function to retrieve employee skills.

By clicking the link of "employee skill record", two ways of query will be provided: looking for employees with any of the selected skills and employees with all the selected skills. This is actually the "or" and "and" relationships.

Log out

Finally, we will introduce the link of "log out", which clears the information of current user from the browser and local Cookie. When clicking the link, first we will see the warning of confirming logging out.

This page requires the user to confirm logging out, and if the user does not want to log out, he or she can just click any of the links on the left. If the user decides to log out, just by clicking the "logout confirmation" button, the system will automatically finish the task of logging off, and redirect the page to the homepage of the system. The corresponding page is Logout.jsp.

At this point, several of the personnel management system based on WEB module are introduced briefly, and the detailed source codes are in the Appendix. Owing to the limitation 
of ability, there is a large gap between the functions of the system and practical requirements, which needs to be improved.

\section{Conclusions}

The basic functions of the system can be implemented smoothly, including department information, accumulative holidays, check time, telephone books, employee skills and logout and so on, so the system is feasible. Some functions such as learning, query statistics and data analysis can be further added according to the needs of users. In the program that has been completed, there are many unsatisfactory algorithms which are not optimized in a unified way, so the system needs to be further improved.

\section{Acknowledgements}

This work was financially supported by project of Technology Department of Jiangxi Province [No 20143BBM26048]and project of Jiangxi University of Technology [No. xtcx201312].

\section{References}

[1] Emile L. Morse. Evaluation Methodologies for Information Management Systems. D-Lib Magazine, 2002, 9. 25-25

[2] Wu Yanjun. Master JSP Programming Techniques. The first edition. Beijing: Post and Telecom Press, 2001. 393-395

[3] Li Shuguang. Instance Analysis of JSP Development. The first edition. Beijing: China Electric Power Press, 2006. 154-157

[4] Zhao Qiang. Master JSP Programming. The first edition. Beijing: Electronics Industry Press, 2006. 342-343

[5] Liu Yongpo. JSP Application Development Technology. The first edition. Beijing: Post and Telecom Press. 2005. 263-265

[6] Deng Ziyun. JSP Network Programming from Basic to Practice. The first edition. Beijing: Publishing House of electronics industry. Electronics Industry Press. 2005. 69-72

[7] Wang Yumei. Thoughts on Information Network Management. Modern Management (working version), 2006, 4:30-30 